\title{
Bilateral Inguinal Hernia Containing both Ovaries in an Infant
}

\author{
Md Mahfuzul Haque ${ }^{1 *}$ \\ Bablu Kumar Saha' \\ Rezbanul Haque ${ }^{1}$ \\ Shamima Nazma ${ }^{2}$ \\ Md Shadrul Alom
}

'Department of Pediatric Surgery

Rangpur Medical College

Rangpur, Bangladesh.

${ }^{2}$ Department of Ophthalmology

Prime Medical College

Rangpur, Bangladesh.

\section{*Correspondence to:}

\section{Dr. Md Mahfuzul Haque}

Registrar

Department of Pediatric Surgery

Rangpur Medical College

Rangpur, Bangladesh.

Mobile: +8801712000017

E-mail:mahfuzps@gmail.com

\begin{abstract}
Inguinal hernia with uncommon contents in the hernia sac has been reported in the literature. Preoperative ultrasound can be helpful to diagnose the presence an uncommon content in the hernia sac. Here we report a rare case of female infant having bilateral inguinal hernia with sac containing ovary and fallopian tube with left sided torsion ovary.
\end{abstract}

Key words: Inguinal hernia; torsion of ovary; herniotomy.

\section{INTRODUCTION}

In both male and female fetuses, inguinal canal development entails a complex sequence of anatomic events involving the gubernaculum and processus vaginalis. In the normally developing female fetus, the processus vaginalis is usually obliterated by 8 months of gestation ${ }^{1}$. In premature infants, because this structure is often patent, an inguinal hernia commonly develops. In female infants, it has been reported to contain the ovary with or without portions of the fallopian tube $15 \%$ to $20 \%$ of the time $^{2}$. Although some hernias regress spontaneously, this is less likely to occur if it contains the ovary, and, in comparison to a bowel-containing hernia, the risk of incarceration is greatly increased ${ }^{2-5}$. The pediatric and surgical literature have described ovary-containing inguinal hernias in neonates and infants ${ }^{1-6}$. In girls, ovaries have a propensity to herniated into the sac and undergo incarceration. If torsion sets in, this may lead to rapid infarction. Once diagnosed to have an ovary in the sac, surgery should be performed as early as possible to prevent such an eventuality. We describe such a case to alert pediatric surgeons not to delay surgery in incarcerated female inguinal hernia which may cause infarction of the ovary.

\section{CASE REPORT}

A 1-month-old girl was brought to the Department of Pediatric Surgery because of bilateral irreducible mass in her both groin. There was history of fever and excessive crying for one day. On physical examination, a $3-\mathrm{cm}$ irreducible right inguinal mass was found. On left side there was reddish swelling which was irreducible and tender. Her temperature was $101^{\circ} \mathrm{F}$, heart rate-110/minute. The abdomen was soft, and no organomegaly was noted. Birth history was unremarkable. The patient was born via spontaneous vaginal delivery and weighed $3200 \mathrm{~g}$ at birth. A sonographic assessment of her right groin showed ovary with peripheral follicles that passed through the left inguinal canal. Doppler sonography revealed normal vascular flow in right, but on 
left side incarcerated ovary found vascular compromise. Sonographic examination of the abdomen showed no abnormalities.

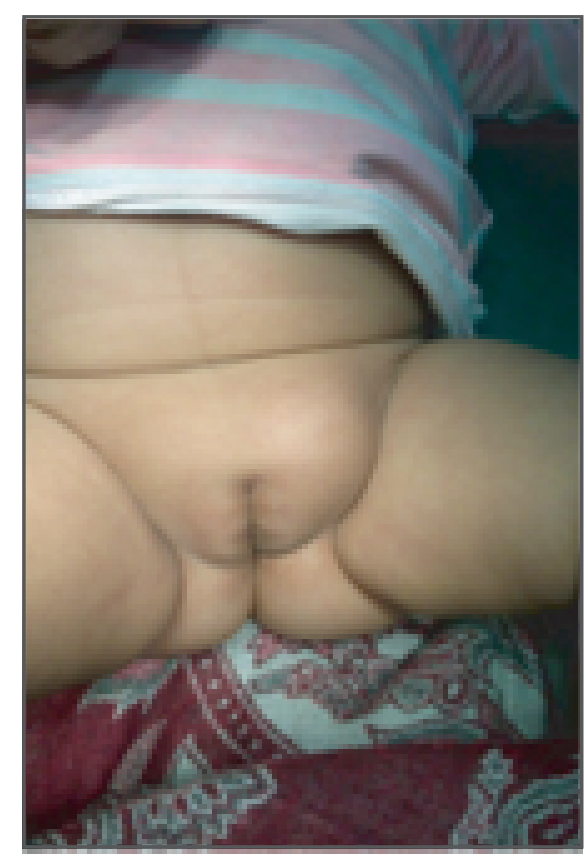

Figure 1: Bilateral inguinal hernia more marked on left side.

Immediately we prepare the baby for emergency surgery. We do laparotomy by pfannenstiel incision for proper evaluation of ovaries with felopian tube. After laparotomy we gently reduce both ovaries internally. Right ovary and tube was healthy but left ovary along with tube was twisted and gangrenous. Left sided sulphingo-ophorectomy and internal herniotomy on both side was done. Post operative period was uneventful and we discharged the patient on fifth day.

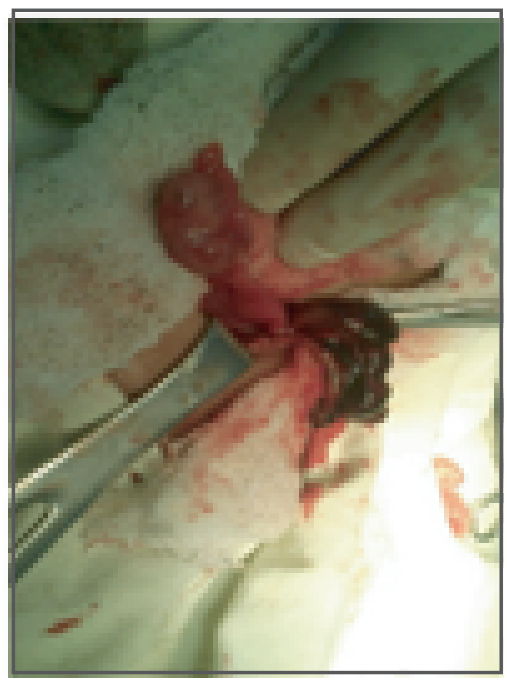

Figure 2: Left infracted fallopian tube and ovary, right reduced healthy ovary.

\section{DISCUSSION}

Inguinal hernia remains one of the most common surgical disorders in children. Literature for inguinal hernia has spanned more than 20 centuries and with new techniques there have been new insights into management as well. Inguinal hernia is a perfect example of a disorder where seemingly a lot has changed whereas in effect nothing much has changed. Inguinal hernia predominantly occurs in males, as girls comprise less than $10 \%$ of all reported cases ${ }^{6}$. Clinically, the child would be brought with a history of inguinal swelling appearing on coughing or crying. Whenever a hernia is suspected in a girl, it is important to be aware of a potential disorder of sexual differentiation. Up to $1-2 \%$ of all female children with hernia would be found to have Androgen insensitivity syndrome ${ }^{7}$. In such a circumstance, a testis may be palpable in the inguinal region. In a girl with inguinal hernia, investigations should be done to rule out Androgen Insensitivity syndrome if there is any suspicion. Though the incidence is very low, it may have important medico legal consequences if CAIS is discovered during surgery and has not been mentioned pre-operatively ${ }^{6}$. But given the low incidence, it is important to proceed with investigations thoroughly. The various investigations include ultrasound and karyotype. Routine screening with karyotype, though most specific may not be feasible for economic and technical reasons except when the hernia sac contains palpable gonads. In girls with only a hernia without a palpable gonad, ultrasound examination from a trained radiologist may be an adequate screening tool. Unequivocal visualization of ovaries with follicles conclusively rules out Androgen insensitivity syndrome. Only in cases where ovaries are not visualized, karyotype may be required. Another adjunctive tool can be measurement of vaginal length in girls with hernias as children with androgen insensitivity syndrome have a shorter vaginal length. Commonly, the contents of the hernia sac are omentum and/ or small bowel. In girls, ovaries have a propensity to herniate into the sac and undergo incarceration ${ }^{4,5}$. If torsion sets in, this may lead to rapid infarction. Once diagnosed to have an ovary in the sac, surgery should be performed as early as possible to prevent such an eventuality ${ }^{8,9}$. Sliding hernias are also known to occur in children where part of the bladder wall or fallopian tubes/ uterus have been found in the hernia defect ${ }^{9}$.

\section{CONCLUSION}

Female infant irreducible hernia should give special attention both in diagnosis and assessment. Early intervention can save vital structure like ovary.

\section{DISCLOSURE}

All the authors declared no competing interest. 


\section{REFERENCES}

1. Huang CS, Luo CC, Chao HC, Chu SM, Yu YJ, Yen JB. The presentation of asymptomatic palpable movable mass in female inguinal hernia. Eur J Pediatr 2003; 162:493-495.

2. Goldstein R, Potts WJ. Inguinal hernia in female infants and children. Ann Surg 1958; 148:819-822.

3. Oudesluys-Murphy AM, Teng HT, Boxma H. Spontaneous regression of clinical inguinal hernias in preterm female infants. J Pediatr Surg 2000; 35:1220-1221.

4. Boley SJ, Cahn D, Lauer L, Weinberg G, Kleinhaus S. The irreducible ovary: a true emergency. J Pediatr Surg 1991; 26:1035-1038

5. Kapur P, Caty MG, Glick PH. Pediatric hernias and hydroceles. Pediatr Clin North Am 1998; 45:773-789.

6. George EK, Oudesluys-Murphy AM, Madern GC, Cleyndert P, Blomjous JG. Inguinal hernias containing the uterus, fallopian tube, and ovary in premature female infants. J Pediatr 2000; 136:696-698.

7. Shadbolt CL, Heinze SB, Dietrich RB. Imaging of groin masses: inguinal anatomy and pathologic conditions revisited. Radiographics 2001; 21(special issue):S261-S271.

8. Moore KL, Persaud TVN. The urogenital system. In: Moore KL, Persaud TVN (eds). The Developing Human: Clinically Oriented Embryology. 7th ed. Philadelphia, PA: WB Saunders Co; 2003; 324-325.

9. Bronsther B, Abrams MW, Elboim C. Inguinal hernias in children: a study of 1,000 cases and a review of the literature. J Am Med Womens Assoc 1972; 27:522-535. 